\title{
Challenges of Sustaining Malaria Community Case Management in 81 Township Hospitals along the China-Myanmar Border Region - Yunnan Province, China, 2020
}

\author{
Wei Ding'; Shenning Lu'; Qiuli Xu'; Xuejiao Ma'; Bei Wang'; Jingbo Xue'; Xiaodong Sun²; \\ Jianwei $\mathrm{Xu}^{2}$; Chris Cotter ${ }^{3}$; Duoquan Wang ${ }^{1, *}$; Yayi Guan'; Ning Xiao ${ }^{1}$
}

\section{Summary \\ What is already known on this topic? \\ The health workforce at township hospitals in the China-Myanmar border region has played a key role in sustaining Community case management of malaria $(\mathrm{CCMm})$, while few studies have investigated their performance and challenges. \\ What is added by this report? \\ Sustaining CCMm in the region was subject to the following major challenges: insufficient training on malaria diagnosis and testing, lacking necessary and timely treatment for patients, and risks of instability among the malaria workforce. \\ What are the implications for public health practice? \\ These challenges called for the national and provincial authorities to provide regular trainings and intensive supervision to strengthen malaria diagnosis and treatment capacity in the region and to set up incentive mechanisms and individual career development paths to sustain the workforce.}

Through years of malaria elimination efforts, China has been on track for the World Health Organization (WHO)'s malaria-free certification after reporting 3 consecutive years of 0 indigenous case since 2017 (1). Sustaining the elimination efforts in the border region of Yunnan Province is critical as it shares a long borderline with Myanmar without natural barriers and faced malaria importation and the risk of reestablishment due to mutual business and population movement (2-4). Community case management of malaria (CCMm) promotes the early detection, prompt testing, and appropriate treatment of malaria in communities. To consolidate the efforts, this study assessed the status of CCMm in 81 township hospitals of 6 border counties in Yunnan in 2020 by investigating the knowledge and practice of health workforce and their challenges in the delivery of malaria diagnostic and treatment services through a structured questionnaire. The results showed that the CCMm was satisfactory for case recognition and testing by rapid diagnostic tests (RDTs), while both training on malaria diagnosis and providing necessary treatment for patients were insufficient, and risks of instability in the malaria workforce existed. It is recommended to provide regular training and intensive supervision for the malaria workforce to identify strategies to sustain the workforce.

The study was conducted from July to December 2020. All relevant malaria health staff (568) of all township hospitals (81) from 6 counties (Yingjiang, Tengchong, Cangyuan, Longling, Longchuan, and Lushui) was included in the study. The 6 counties were selected out of 18 total border counties by having a higher number of imported malaria cases in the border region between January 1, 2017 and December 31, 2019 according to the data from China Information System for Disease Control and Prevention (CISDCP).

The questionnaire was generated using an online survey tool Wenjuanxing (WJX, https://www.wjx.cn/, in Chinese) and was pretested among 32 health staff in Tengchong County and Simao County. The finalized questionnaire was delivered to the targeted respondents by a mobile application and administrated by the field investigators of local CDCs. Written informed consent was obtained from each respondent. Results were collected by WJX and analyzed by Microsoft Office Excel (version 2019; Microsoft Corp, Beijing, China).

The average age of the respondents was $32.15 \pm 8.40$ years and $53.7 \%(305 / 568)$ were aged between $30-50$ years; $88.4 \%$ (502/568) had bachelor's degree or junior college degree in medicine. Among all the respondents, $44.7 \%(254 / 568)$ were physicians responsible for the diagnosis and treatment of malaria, 26.4\% (150/568) were lab technicians responsible for testing the malaria suspects, and $28.9 \%(164 / 568)$ were public health 
doctors responsible for reporting infectious diseases and conducting epidemiological investigations.

Most physicians $(94.9 \%, 241 / 254)$ would suspect malaria if any patient presented symptoms including chills, fever, and shivering. However, half (50\%, 127/254) of the respondents had not received any training on diagnosis and treatment of malaria over the past 3 years, and nearly one-third $(33.1 \%, 84 / 254)$ of respondents had never had a patient with malaria infection during their practice. In addition, $53.5 \%$ of respondents did not provide malaria treatment in local hospitals (Table 1).

Most lab technicians had knowledge of $(96.7 \%$, $145 / 150)$ and were capable $(90.7 \%, 136 / 150)$ of using RDTs, while $55.3 \%$ (83/150) of them were not adequately trained for preparing blood films, and 47.3\% (71/150) could not identify Plasmodium species through microscopy. Only 50.7\% (76/150) were trained on microscopy examination of Plasmodium during the past 3 years (Table 2).

Among the 164 public health doctors, 29.3\% (48/164) reported a lack of regular review of blood films by local county CDCs. Over a quarter $(28.7 \%$, 47/164) mentioned shortages of necessary anti-malarial drugs in their hospitals. Almost every respondent $(99.4 \%, 163 / 164)$ was engaged in the malaria health education activities, while the promotion via official WeChat account only made up for $26.2 \%$ (43/174). In addition, $68.3 \%(112 / 164)$ reported "no change" in terms of the number of malaria health staffs during the last 3 years. Inadequate training $(70.7 \%, 116 / 164)$ and professional movement $(59.8 \%, 98 / 164)$ stood out as 2 major challenges (Table 3 ).

\section{DISCUSSION}

This study assessed the knowledge and practices of the physicians, lab technicians, and public health doctors who worked at the township hospitals in border counties in Yunnan and the challenges during their work on malaria. Positive findings from the study included the following: local township health staff at the Yunnan border area was relatively young and well educated; physicians were vigilant in recognizing the

TABLE 1. Physicians' knowledge and practice of malaria diagnosis and treatment in the 81 township hospitals of 6 border counties, Yunnan Province, 2020.

\begin{tabular}{|c|c|c|c|c|c|c|c|}
\hline Variable & $\begin{array}{c}\text { Yingjiang, } \\
\mathrm{n}(\%)\end{array}$ & $\begin{array}{c}\text { Tengchong, } \\
\mathrm{n}(\%)\end{array}$ & $\begin{array}{c}\text { Cangyuan, } \\
\mathrm{n}(\%)\end{array}$ & $\begin{array}{c}\text { Longling, } \\
\mathrm{n}(\%)\end{array}$ & $\begin{array}{c}\text { Longchuan, } \\
\text { n (\%) }\end{array}$ & $\begin{array}{c}\text { Lushui, } \\
\text { n (\%) }\end{array}$ & $\begin{array}{l}\text { Total, } \\
\text { n (\%) }\end{array}$ \\
\hline \multicolumn{8}{|c|}{ Knowledge of malaria symptoms } \\
\hline Yes & $49(98.0)$ & $71(94.7)$ & $17(77.3)$ & 46 (97.9) & $21(95.5)$ & $37(97.4)$ & $241(94.9)$ \\
\hline No & $1(2.0)$ & $4(5.3)$ & $5(22.7)$ & $1(2.1)$ & $1(4.6)$ & $1(2.6)$ & $13(5.1)$ \\
\hline \multicolumn{8}{|c|}{ Trained in last 3 years } \\
\hline Yes & $37(74.0)$ & $28(37.3)$ & $7(31.8)$ & $28(59.6)$ & $10(45.5)$ & $17(44.7)$ & $127(50.0)$ \\
\hline No & $13(26.0)$ & $47(62.7)$ & $15(68.2)$ & $19(40.4)$ & $12(54.6)$ & $21(55.3)$ & $127(50.0)$ \\
\hline \multicolumn{8}{|c|}{ Recognize high-risk groups } \\
\hline Returnees & $49(98.0)$ & $72(96.0)$ & $18(81.8)$ & $43(91.5)$ & $19(86.4)$ & $32(84.2)$ & $223(87.8)$ \\
\hline Migrants & $43(86.0)$ & $67(89.3)$ & $16(72.7)$ & $44(93.6)$ & $18(81.8)$ & $32(84.2)$ & $220(86.6)$ \\
\hline Women & $11(22.0)$ & $16(21.3)$ & $4(25.0)$ & $13(27.7)$ & $9(40.9)$ & $9(23.7)$ & $62(24.4)$ \\
\hline Children & $13(26.0)$ & $22(29.3)$ & $7(43.8)$ & 15 (31.9) & $8(36.4)$ & $11(29.0)$ & $76(29.9)$ \\
\hline Others & $1(2.0)$ & $4(5.3)$ & $4(25.0)$ & $2(4.3)$ & $0(0.0)$ & $1(2.6)$ & $12(4.7)$ \\
\hline \multicolumn{8}{|l|}{ Provided treatment } \\
\hline Yes & $31(62.0)$ & $35(46.7)$ & 15 (68.2) & $23(48.9)$ & $8(36.4)$ & $6(15.8)$ & $118(46.5)$ \\
\hline No & $19(38.0)$ & $40(53.3)$ & $7(31.8)$ & $24(51.1)$ & $14(63.6)$ & $32(84.2)$ & $136(53.5)$ \\
\hline \multicolumn{8}{|c|}{ Last malaria patient received } \\
\hline Never & $11(22.0)$ & $13(17.3)$ & $9(40.9)$ & $21(44.7)$ & $10(45.5)$ & $20(52.6)$ & $84(33.1)$ \\
\hline$<5$ years ago & $19(38.0)$ & $23(30.7)$ & $5(22.7)$ & $8(17.0)$ & $6(27.3)$ & $3(7.9)$ & $64(25.2)$ \\
\hline $5-10$ years ago & $14(28.0)$ & $23(30.7)$ & $3(13.6)$ & $10(21.3)$ & $3(13.6)$ & $8(21.1)$ & $61(24.0)$ \\
\hline$>10$ years ago & $6(12.0)$ & $16(21.3)$ & $5(22.7)$ & $8(17.0)$ & $3(13.6)$ & $7(18.4)$ & $45(17.7)$ \\
\hline Total & $50(19.7)$ & $75(29.5)$ & $22(8.7)$ & $47(18.5)$ & $22(8.7)$ & $38(15.0)$ & $254(100.0)$ \\
\hline
\end{tabular}


TABLE 2. Lab technicians' knowledge and practice on malaria testing including use of rapid diagnostic tests (RDTs) in the 81 township hospitals of 6 border counties, Yunnan Province, 2020.

\begin{tabular}{|c|c|c|c|c|c|c|c|}
\hline Variable & $\begin{array}{c}\text { Yingjiang, } \\
\mathrm{n}(\%)\end{array}$ & $\begin{array}{c}\text { Tengchong, } \\
\mathrm{n}(\%)\end{array}$ & $\begin{array}{c}\text { Cangyuan, } \\
\text { n (\%) }\end{array}$ & $\begin{array}{c}\text { Longling, } \\
\mathrm{n}(\%)\end{array}$ & $\begin{array}{c}\text { Longchuan, } \\
\mathrm{n}(\%)\end{array}$ & $\begin{array}{c}\text { Lushui, } \\
\text { n (\%) }\end{array}$ & $\begin{array}{l}\text { Total, } \\
\text { n (\%) }\end{array}$ \\
\hline \multicolumn{8}{|l|}{ Know about RDTs } \\
\hline Yes & $33(100.0)$ & $32(94.1)$ & $20(95.2)$ & $28(100.0)$ & $16(100.0)$ & $16(88.9)$ & $145(96.7)$ \\
\hline No & $0(0)$ & $2(5.9)$ & $1(4.8)$ & $0(0)$ & $0(0)$ & $2(11.1)$ & $5(3.3)$ \\
\hline \multicolumn{8}{|l|}{ Be able to use RDTs } \\
\hline Yes & $33(100.0)$ & $29(85.3)$ & $20(95.2)$ & $26(92.9)$ & $16(100.0)$ & $12(66.7)$ & $136(90.7)$ \\
\hline No & $0(0)$ & $5(14.7)$ & $1(4.8)$ & $2(7.1)$ & $0(0)$ & $6(33.3)$ & $14(9.3)$ \\
\hline \multicolumn{8}{|l|}{ Use RDTs in daily work } \\
\hline Always & $11(33.3)$ & $13(38.2)$ & $4(19.1)$ & $19(67.9)$ & $4(25.0)$ & $0(0)$ & $51(34.0)$ \\
\hline Sometimes & $22(66.7)$ & $16(47.1)$ & $15(71.4)$ & $7(25.0)$ & $11(68.8)$ & $10(55.6)$ & $81(54.0)$ \\
\hline Never & $0(0.0)$ & $5(14.7)$ & $2(9.5)$ & $2(7.1)$ & $1(6.3)$ & $8(44.4)$ & $18(12.0)$ \\
\hline \multicolumn{8}{|l|}{ Blood film preparation } \\
\hline Skillful & $15(45.5)$ & $13(38.2)$ & $8(38.1)$ & $10(35.7)$ & $5(31.3)$ & $8(44.4)$ & $59(39.3)$ \\
\hline Not skillful & $13(39.4)$ & $20(58.8)$ & $13(61.90)$ & $18(64.3)$ & $10(62.5)$ & $9(50.0)$ & $83(55.3)$ \\
\hline No & $5(15.2)$ & $1(2.9)$ & $0(0)$ & $0(0)$ & $1(6.3)$ & $1(5.6)$ & $8(5.3)$ \\
\hline \multicolumn{8}{|c|}{ Received microscopy training } \\
\hline Yes & $16(48.5)$ & $16(47.1)$ & $7(33.3)$ & $19(67.9)$ & $5(31.3)$ & $13(72.2)$ & $76(50.7)$ \\
\hline No & $17(51.5)$ & $18(52.9)$ & $14(66.7)$ & $9(32.1)$ & $11(68.8)$ & $5(27.8)$ & $74(49.3)$ \\
\hline \multicolumn{8}{|l|}{ Microscopy ability } \\
\hline Can identify species & $16(48.5)$ & $18(52.9)$ & $6(28.6)$ & $7(25.0)$ & $3(18.8)$ & $5(27.8)$ & $55(36.7)$ \\
\hline Cannot identify species & $10(30.3)$ & $11(32.4)$ & $11(52.4)$ & $18(64.3)$ & $10(62.5)$ & $11(61.1)$ & $71(47.3)$ \\
\hline No & $7(21.2)$ & $5(14.7)$ & $4(19.1)$ & $3(10.7)$ & $3(18.8)$ & $2(11.1)$ & $24(16.0)$ \\
\hline \multicolumn{8}{|c|}{ RDTs stock outs in last 1 year } \\
\hline Yes & $1(3.0)$ & $1(2.9)$ & $1(4.8)$ & $1(3.6)$ & $1(6.3)$ & $0(0)$ & $5(3.3)$ \\
\hline No & $32(97.0)$ & $33(97.1)$ & $20(95.2)$ & $27(96.4)$ & $15(93.8)$ & $18(100)$ & $145(96.7)$ \\
\hline Total & $33(22.0)$ & $34(22.7)$ & $21(14.0)$ & $28(18.7)$ & $16(10.7)$ & $18(12.0)$ & $150(100.0)$ \\
\hline
\end{tabular}

malaria patients; and almost all lab technicians knew and were able to use RDTs. Challenges were also identified in three aspects. First, there was insufficient training on malaria diagnosis and testing. The results showed that lab technicians had a low proficiency in preparing blood films and public health doctors regarded lacking adequate training for malaria as one of their major challenges in work. The findings were consistent with the previous studies $(5-7)$ that suggested that training the malaria workforce was urgently required to sustain the malaria diagnosis and treatment capacity in the post-elimination era. Second, there was a lack of necessary treatment for patients. Only $46 \%$ of the interviewed physicians confirmed providing the necessary treatments to patients that had been diagnosed with malaria, which might partially be linked to a shortage of antimalarials. Nevertheless, delayed treatment would threaten the life of severe malaria patients and might leave untreated patients become indirect infection sources that lead to a secondary infection from imported cases. Finally, there were risks of instability among the local malaria workforce. Although the movement of malaria health staff was not obvious, $59.8 \%$ and $36.0 \%$ of the public health doctors regarded the instability (movement) of staff and the aging of experienced staff as challenges. According to our follow-up interviews, with the elimination of malaria, fewer cases were received in local township hospitals (some hospitals have even not received any malaria patients in the past 3 years), which might explain the shift of the malaria workforce. On the other hand, experienced staff tends to get into upper-level medical facilities once they accumulate enough experiences at the township level and this would contribute to losses of the experienced malaria workforce. 
TABLE 3. Public health doctors' knowledge and practice on malaria case management and the challenges in the 81 township hospitals of 6 border counties, Yunnan Province, 2020.

\begin{tabular}{|c|c|c|c|c|c|c|c|}
\hline Variable & $\begin{array}{c}\text { Yingjiang, } \\
\mathrm{n}(\%)\end{array}$ & $\begin{array}{c}\text { Tengchong, } \\
\mathrm{n}(\%)\end{array}$ & $\begin{array}{c}\text { Cangyuan, } \\
\mathrm{n}(\%)\end{array}$ & $\begin{array}{c}\text { Longling, } \\
\mathrm{n}(\%)\end{array}$ & $\begin{array}{c}\text { Longchuan, } \\
\text { n (\%) }\end{array}$ & $\begin{array}{c}\text { Lushui, } \\
\text { n (\%) }\end{array}$ & $\begin{array}{l}\text { Total, } \\
\mathrm{n}(\%)\end{array}$ \\
\hline \multicolumn{8}{|l|}{ Review of blood films } \\
\hline Yes & $21(72.4)$ & $30(73.2)$ & $12(80.0)$ & $28(90.3)$ & $7(41.2)$ & $18(58.1)$ & $116(70.7)$ \\
\hline No & $8(27.6)$ & $11(26.8)$ & $3(20.0)$ & $3(9.7)$ & $10(58.8)$ & $13(41.9)$ & $48(29.3)$ \\
\hline \multicolumn{8}{|l|}{ Assist in case investigation } \\
\hline Perform case survey & $19(65.5)$ & $28(68.3)$ & $10(66.7)$ & $29(93.6)$ & $12(70.6)$ & $22(71.0)$ & $120(73.2)$ \\
\hline Provide case information & $7(24.1)$ & $11(26.8)$ & $5(33.3)$ & $2(6.5)$ & $3(17.7)$ & $7(22.6)$ & $35(21.3)$ \\
\hline Others & $1(3.4)$ & $2(4.9)$ & $0(0)$ & $0(0)$ & $0(0)$ & $0(0)$ & $3(1.8)$ \\
\hline No & $2(6.9)$ & $0(0)$ & $0(0)$ & $0(0)$ & $2(11.8)$ & $2(6.45)$ & $6(3.7)$ \\
\hline \multicolumn{8}{|l|}{ Assist in foci response } \\
\hline Fill in registration form & $21(72.4)$ & $27(65.8)$ & $7(46.7)$ & $28(90.3)$ & $7(41.2)$ & $26(83.87)$ & $116(70.7)$ \\
\hline Survey of companions & $5(17.2)$ & $7(17.1)$ & $2(13.3)$ & $2(6.5)$ & $4(23.5)$ & $2(6.45)$ & $22(13.4)$ \\
\hline Vector investigation & $0(0)$ & $0(0)$ & $2(13.3)$ & $0(0)$ & $0(0)$ & $0(0)$ & $2(1.2)$ \\
\hline Vector control & $0(0)$ & $0(0)$ & $0(0)$ & $0(0)$ & $1(5.9)$ & $0(0)$ & $1(0.6)$ \\
\hline Health education & $1(3.5)$ & $8(19.5)$ & $4(26.7)$ & $1(3.2)$ & $2(11.8)$ & $1(3.23)$ & $17(10.4)$ \\
\hline No & $2(6.9)$ & $0(0)$ & $0(0)$ & $0(0)$ & $3(17.7)$ & $2(6.5)$ & $7(4.3)$ \\
\hline \multicolumn{8}{|l|}{ Antimalarials in stock } \\
\hline Yes & $20(69.0)$ & $34(82.9)$ & $10(66.7)$ & $30(96.8)$ & $9(52.9)$ & $14(45.2)$ & $117(71.3)$ \\
\hline No & $9(31.0)$ & $7(17.1)$ & $5(33.3)$ & $1(3.2)$ & $8(47.1)$ & $17(54.8)$ & $47(28.7)$ \\
\hline \multicolumn{8}{|l|}{ Health education } \\
\hline Provide leaflets in hospital & $21(72.4)$ & $29(70.7)$ & $15(100.0)$ & $27(87.1)$ & $14(82.4)$ & $24(77.4)$ & $130(79.3)$ \\
\hline Malaria Day campaign & $18(62.1)$ & $39(95.1)$ & $11(73.3)$ & $26(83.9)$ & $9(52.9)$ & $22(71.0)$ & $125(76.2)$ \\
\hline Promotion in villages & $22(75.9)$ & $28(68.29)$ & $11(73.3)$ & $21(67.7)$ & $13(76.5)$ & $24(77.4)$ & $119(72.6)$ \\
\hline Promotion via WeChat & $5(17.2)$ & $14(34.15)$ & $4(26.67)$ & $15(48.4)$ & $2(11.8)$ & $3(9.7)$ & $43(26.2)$ \\
\hline No & $0(0)$ & $0(0)$ & $0(0)$ & $0(0)$ & $0(0)$ & $1(3.2)$ & $1(0.6)$ \\
\hline \multicolumn{8}{|l|}{ Movement of malaria staff } \\
\hline Increase & $10(34.5)$ & $7(17.1)$ & $5(33.3)$ & $0(0)$ & $3(17.7)$ & $5(16.1)$ & $30(18.3)$ \\
\hline Reduce & $4(13.8)$ & $1(2.4)$ & $0(0)$ & $2(6.5)$ & $1(5.9)$ & $5(16.1)$ & $13(7.9)$ \\
\hline No change & $15(51.7)$ & $31(75.6)$ & $10(66.7)$ & $28(90.3)$ & 9 (52.9) & $19(61.3)$ & $112(68.3)$ \\
\hline Unknown & $0(0)$ & $2(4.9)$ & $0(0)$ & $1(3.2)$ & $4(23.5)$ & $2(6.5)$ & $9(5.5)$ \\
\hline \multicolumn{8}{|l|}{ Malaria-related work } \\
\hline Radical treatment & $9(31.0)$ & $21(51.2)$ & $6(40.0)$ & $21(67.7)$ & $5(25.4)$ & $8(25.8)$ & $70(42.7)$ \\
\hline Insecticide spray & $26(89.7)$ & $23(56.1)$ & $14(93.3)$ & $20(64.5)$ & $13(76.5)$ & $22(71.0)$ & $118(72.0)$ \\
\hline Promote nets use & $23(79.3)$ & $31(75.6)$ & $11(73.3)$ & $20(64.5)$ & $16(94.12)$ & $23(74.2)$ & $124(75.6)$ \\
\hline Distribute antimalarials & $17(58.6)$ & $31(75.6)$ & $11(73.3)$ & $28(90.3)$ & $12(70.6)$ & $23(74.2)$ & $122(74.4)$ \\
\hline \multicolumn{8}{|l|}{ Challenges } \\
\hline Staff shifting & $17(58.6)$ & $22(53.7)$ & $8(53.3)$ & $20(64.5)$ & $7(41.2)$ & $24(77.4)$ & $98(59.8)$ \\
\hline Aging of experienced staff & $10(34.5)$ & $17(41.5)$ & $6(40.0)$ & $8(25.8)$ & $5(29.4)$ & $13(41.9)$ & $59(36.0)$ \\
\hline Lack motivation & $9(31.0)$ & $8(19.5)$ & $1(6.7)$ & $8(25.8)$ & $4(23.5)$ & $9(29.0)$ & $39(23.8)$ \\
\hline Heavy workload & $14(48.3)$ & $20(48.8)$ & $12(80.0)$ & $9(29.0)$ & $4(23.5)$ & $17(54.8)$ & $76(46.3)$ \\
\hline Inadequate training & $21(72.4)$ & $28(68.3)$ & $9(60.0)$ & $24(77.4)$ & $13(76.5)$ & $21(67.7)$ & $116(70.7)$ \\
\hline Others & $1(3.5)$ & $2(4.9)$ & $1(6.7)$ & $0(0)$ & $0(0)$ & $0(0)$ & $4(2.4)$ \\
\hline \multicolumn{8}{|l|}{ Impacted by COVID-19 } \\
\hline Yes & $6(20.7)$ & $14(34.2)$ & $4(26.7)$ & $5(16.1)$ & $1(5.9)$ & $7(22.6)$ & $37(22.6)$ \\
\hline No & $23(79.3)$ & $27(65.9)$ & $11(73.3)$ & $26(83.9)$ & $16(94.1)$ & $24(77.4)$ & $127(77.4)$ \\
\hline Total & $29(17.7)$ & $41(25.0)$ & $15(9.1)$ & $31(18.9)$ & $17(10.4)$ & $31(18.9)$ & $164(100.0)$ \\
\hline
\end{tabular}


According to the WHO framework of malaria elimination (8), maintaining the malaria technical expertise and sustaining financial and political commitment at national and subnational levels are among the key points for countries to prevent reestablishment of malaria transmission. In this regard, it is necessary for local government of the border region to sustain their current efforts, with additional focus on training the local health workforce; increasing supervision on malaria testing and treatment; strengthening the capacities on risk identification; and sustaining the local malaria workforce through certain strategies such as include the stability of malaria workforce as a key performance indicator in health facilities. Yunnan's malaria diagnostic reference laboratory has improved the standardization of blood examination in the province since its establishment in 2012 (7). It is recommended to reinforce its function in the training of lab technicians and supervision of the quality on slide preparation. Raising the malaria awareness of the public and the targeted groups is also recommended. As most malaria patients admitted in hospitals were the returning laborers who worked in construction sites, lumbering and mine industry (9), we encourage local health facilities to increase use of social applications such as WeChat [the most widely used mobile social application in China, which has proven improvement in efficiency of public health education (10)] for disseminating information on malaria prevention among the general public and targeted groups including the laborers and the related companies to provide tailored information.

The study was subject to at least two limitations: First, selection of the study groups might not capture all relevant information. For instance, the performance of case notification was not assessed because the duty falls into different positions across hospitals, and those who are responsible for case notification might not be covered in the study. Second, the respondents were subject to potential recall bias. The answers of the respondents were not capable of being cross verified as the study did not cover patients or the hospitals' administrators.

In conclusion, the CCMm in Yunnan border townships has performed satisfactorily in terms of case detection and testing by RDTs, whereas training on both malaria case diagnosis and treatment is insufficient and the risk of workforce instability exists. It is recommended to provide regular training and intensive supervision to strengthen the malaria diagnosis and treatment capacity in the region and to set up incentive mechanisms and individual career development path to sustain the workforce.

Funding: the UNICEF/UNDP/World Bank/WHO Special Program for Research and Training in Tropical Diseases (TDR) Small Grant (WHO Reference 2021/1104003-0) and the program of the Chinese Center for Tropical Diseases Research (No. $131031104000160004)$.

\section{doi: $10.46234 / \mathrm{ccdcw} 2021.097$}

\# Corresponding author: Duoquan Wang, wangdq@nipd.chinacdc.cn.

\begin{abstract}
${ }^{1}$ National Institute of Parasitic Diseases, Chinese Center for Disease Control and Prevention (Chinese Center for Tropical Diseases Research); NHC Key Laboratory of Parasite and Vector Biology; WHO Collaborating Centre for Tropical Diseases; National Center for International Research on Tropical Diseases, Shanghai, China; 2 Yunnan Institute of Parasitic Diseases, Puer, Yunnan, China; ${ }^{3}$ Malaria Elimination Initiative, Institute for Global Health Sciences, University of California, San Francisco, CA, USA.
\end{abstract}

Submitted: March 02, 2021; Accepted: April 21, 2021

\section{REFERENCES}

1. Feng J, Zhang L, Huang F, Yin JH, Tu H, Xia ZG, et al. Ready for malaria elimination: zero indigenous case reported in the People's Republic of China. Malar J 2018;17(1):315. http://dx.doi.org/10.1186/ s12936-018-2444-9.

2. Feng J, Tu H, Zhang L, Xia ZG, Zhou SS. Vital surveillances: imported malaria cases-China, 2012-2018. China CDC Wkly 2020;2(17): 277 - 84. http://dx.doi.org/10.46234/ccdcw2020.072.

3. Zhu GD, Cao J. Challenges and countermeasures on Chinese malaria elimination programme during the coronavirus disease (COVID-19) outbreak. Chin J Schisto Control 2020;32(1):7 - 9. http://dx.doi.org/ 10.16250/j.32.1374.2020036. (In Chinese).

4. Wang DQ, Cotter C, Sun XD, Bennett A, Gosling RD, Xiao N. Adapting the local response for malaria elimination through evaluation of the 1-3-7 system performance in the China-Myanmar border region. Malar J 2017;16(1):54. http://dx.doi.org/10.1186/s12936-017-1707-1.

5. Xian Y, Wang ML, Shao T, Hu T, He ZF, Liu CY, et al. Analysis on the evolution and trend of malaria prevention and control policies in China. Chin J Health Pol 2017;10(3):70 - 4. http://dx.doi.org/10. 3969/j.issn.1674-2982.2017.03.012. (In Chinese).

6. Wang JZ, Feng J, Li XS, Li SG, Wang XJ, Yang DH, et al. Analysis of imported malaria in Tengchong City, Yunnan Province during 20162019. Chin J Parasitol Parasit Dis 2020;38(4):435 - 9. http://dx. doi.org/CN/Y2020/V38/I4/435. (In Chinese).

7. Xu YC, Deng Y, Zhang CL, Chen MN, Liu H, Xue JB, et al. Analysis of the quality of review and laboratory diagnosis of malaria cases in Yunnan Province in 2017. J Pathogen Biol 2018;13(10):1103-8. http://dx.doi.org/10.13350/j.cjpb.181010. (In Chinese).

8. Global Malaria Programme. A framework for malaria elimination. Geneva: WHO, 2017. https://www.who.int/malaria/publications/atoz/ 9789241511988/en/.

9. Jiang T, Yang LL, Wang SQ, Wu XF, Wang TY, Li YL, et al. Epidemiological and clinical characteristics of 623 malaria inpatients in Tengchong, Yunnan Province. China J Infect Dis 2017;35(7):420 - 1. http://dx.doi.org/10.3760/cma.j.issn.1000-6680.2017.07.009. (In Chinese).

10. Wang LP, Huang LC, Xu H, Yang J, Shen JJ. Application of a WeChat public account in health education and health promotion. Chin J Health Edu 2017;33(7):669 - 71. http://dx.doi.org/10.16168/j.cnki.issn. 1002-9982.2017.07.024. (In Chinese). 